\title{
CARTEIRAS DIGITAIS: O FUTURO DOS PAGAMENTOS MÓVEIS
} DIGITAL WALLETS: THE FUTURE OF MOBILE PAYMENTS

\author{
Luiz Antônio da Silva Gonçalves ${ }^{1}$ \\ Márcia Rego Sampaio de Almeida ${ }^{2}$ \\ Lucio Dias das Neves ${ }^{3}$ \\ Jonas Santiago de Andrade 4 \\ Eduardo Muniz Santana Bastos ${ }^{5}$
}

\begin{abstract}
RESUMO: O presente estudo tem como proposta analisar as nuances das patentes nacionais e internacionais relacionadas ao mercado das e-wallet (carteira digital, em português). A carteira digital trata-se de uma solução eletrônica, que permite o armazenamento de dados financeiros e pessoais, para que possam ser utilizados, posteriormente, em operações financeiras e comerciais. Neste trabalho, foi realizada uma prospecção tecnológica relacionada ao tema proposto por meio de ampla exploração nas bases de dados de patentes, operando a plataforma do Questel Orbit. A investigação desempenhada em setembro de 2021 encontrou um montante de 114 tecnologias protegidas, mundialmente, no período abrangido de 1998 a 2019. Os resultados mostram que as mudanças tecnológicas inseridas no sistema digital de pagamento têm sido incorporadas em diversos países, demonstrando assim, uma inclusão financeira na escolha desse modelo de pagamento pelos consumidores. Porém, para garantir a confiabilidade nos sistemas digitais de pagamento será imprescindível a segurança da informação garantida pelas empresas responsáveis pelo serviço, obedecendo às legislações específicas do setor tecnológico.
\end{abstract}

Palavras-chave: Carteira Digital. Pagamento Eletrônico. Prospecção. Patente.

ABSTRACT: This study aims to analyze the nuances of national and international patents related to the e wallet market (digital wallet, in Portuguese). The digital wallet is an electronic solution that allows the storage of financial and personal data, so that they can be used, later, in financial and commercial operations. In this work, a technological prospecting related to the proposed theme was carried out through extensive exploration in the patent databases, operating the Questel Orbit platform. The research carried out in September 2021 found II4 protected technologies, worldwide, in the period covered from 1998 to 2019. The results show that the technological changes inserted in the digital payment system have been incorporated in several countries, thus demonstrating a financial inclusion in the choice of this payment model by consumers. However, in order to guarantee the reliability of digital payment systems, the information security guaranteed by the companies responsible for the service will be essential, obeying the specific legislation of the technological sector.

Keywords: Digital Wallet. Electronic Payment. Prospecting. Patent.

\footnotetext{
${ }^{I}$ Doutorando em Difusão do Conhecimento pela Universidade Federal da Bahia, DMMDC/UFBA e Mestre em Propriedade Intelectual e Transferência de Tecnologia para Inovação pela Universidade Federal da Bahia, PROFNIT/UFBA. Graduado em Administração.

${ }^{2}$ Mestra em Propriedade Intelectual e Transferência de Tecnologia para a Inovação- PROFNIT/UFBA. Graduado em Secretariado Executivo.

${ }^{3}$ Doutorando em Comunicação, Cultura e Amazônia - PPGCOM/UFPA, Mestre em Propriedade Intelectual e Transferência de Tecnologia para Inovação - PROFNIT/UNIFAP e Professor do Instituto Federal de Educação, Ciência e Tecnologia do Amapá/IFAP. Graduado em Comunicação Social/Relações Públicas. Universidade Federal do Pará/UFPA.

4 Especialista em Gestão Pública pela Universidade Federal da Bahia - UFBA e em Docência para Educação Profissional e Tecnológica (DocentEPT) pelo Instituto Federal do Espirito Santo - IFES. Atualmente, professor da Educação Profissional e Tecnológica. Graduado em Administração. Universidade Estadual da Bahia/UNEB.

5 Doutor em Biotecnologia pela Universidade Federal da Bahia/UFBA. Estágio Pós-Doutoral no Programa em Propriedade Intelectual e Transferência de Tecnologia para a Inovação, PROFNIT/UFBA. Graduado em Farmácia.

Endereço profissional: Universidade Federal da Bahia, Laboratório de Neuroquímica - LABNQ/ ICS (UFBA). Instituto de Ciência da Saúde, Canela, 40rogoz - Salvador, BA - Brasil. Universidade Federal da Bahia/UFBA.
} 


\section{INTRODUÇÃO}

$\mathrm{O}$ uso da prospeç̧ão tecnológica tem-se mostrado uma ferramenta eficaz como instrumento de decisão pelas instituições ligadas à Pesquisa, Ciência, Tecnologia \& Inovação (PCT\&I), quanto à possível proteção intelectual dos seus ativos. Este meio de investigação permite a verificação do estado da técnica no cenário global das patentes e da literatura como um dos métodos, dentre os existentes, capaz de analisar os principais detentores e concorrentes dos segmentos específicos tecnológicos, autores expressivos, linha do tempo de publicações, inovações, classificação internacional de patentes (IPC), principais países depositantes etc. (AMPARO et al., 2012).

Neste trabalho será abordado o estado da arte das soluções digitais de pagamento, enfatizando as carteiras digitais ou e-wallet (em inglês), tecnologia disruptiva incorporada às transações - financeiras, econômicas e comerciais -, e quais os principais impactos provocados por essas inovações tecnológicas ao cotidiano do consumidor - suas causas e consequências.

Historicamente, nossos antepassados empregavam o escambo como meio de troca de mercadorias utilizando o gado e o sal, como moeda para cambiar produtos, uma vez que não existia pagamento à época. A posteriori, o dinheiro começou como um simples artigo de cobre, prata, conchas e ouro, evoluindo para moedas e notas em papel, cheques, contas correntes, números em livros-razão, cartões plásticos, informações eletrônicas em telas de computadores $\mathrm{e}$, atualmente, com os avanços tecnológicos surgiram os dígitos armazenados em chips de silicone, bitcoin- moeda digital ou criptomoeda - como novas alternativas para o futuro do dinheiro e opções de pagamentos para o usuário. A tecnologia que está por trás das transações de criptomoedas como o bitcoin é a blockchain (GLOBO, 2018).

A Blockchain é uma tecnologia utilizada para possibilitar as negociações financeiras de moedas digitais sem a necessidade de intermediários. As transações são realizadas peer to peer (ponto a ponto ou pessoa a pessoa em português) para troca de informações confidenciais, firmamento de contratos, rastreamento de produtos, transferência de valores, e têm como características a segurança, a integridade, a garantia, a privacidade e a redução de tempo e de dinheiro. A moeda digital mais difundida é a bitcoin, criada há mais de io anos como uma moeda alternativa de troca, porém existem outras moedas digitais como o LTC do Litecoin, a XRP da Ripple e a Nano. O sucesso creditado à criptomoeda deve-se à confiança em cada transação realizada, despertando tanto o interesse do setor público como o privado (GLOBO, 2018).

Com o início dos serviços bancários oferecidos pela Internet e o aumento das carteiras digitais, os consumidores puderam optar por novas possibilidades na realização de transações 
financeiras com o toque de um dedo. As carteiras digitais fazem parte dos componentes vitais, que impulsionam o crescimento do comércio eletrônico.

A China foi o país precursor no cenário mundial a iniciar os serviços de pagamentos on-line e o uso do telefone móvel para a realização de operações comerciais e financeiras. Sendo, atualmente, a líder no segmento de carteiras digitais (ADYEN, 2019). Por não ter adotado o sistema de pagamento por cartão de crédito, inicialmente, Hong Kong desenvolveu uma tecnologia específica para a utilização e-wallet para efetuar o pagamento das tarifas nos transportes públicos através de débitos on-line, e aos poucos essa tecnologia disruptiva foi sendo introduzida na rotina da população chinesa para as diversas despesas de pequenos valores. (SILVA, 2017).

Em 2004, a China iniciou as carteiras digitais nas plataformas de compras no site da Taobao, por meio do Alipay - maior plataforma de pagamentos móveis do mundo, utilizando ainda os pagamentos off-line, realizados por meio de código de barras (SILVA, p.28, 2017).

No cenário brasileiro, continuam se mostrando algumas das maiores tendências do cenário financeiro atual. E, nos próximos anos, as carteiras digitais serão grandes forças de revolução no mercado. O Banco Central do Brasil projetou a modalidade de pagamento instantâneo, cuja modalidade trata-se de uma transação eletrônica rápida efetuada por meio de um dispositivo móvel como celular, tablete, smart watch aceitos em qualquer instituição, similares aos utilizados pelo Mercado Pago e PicPay. Essa espécie de pagamento almeja substituir o TED, o DOC e o cartão físico, utilizando a Chave Pix (BRASIL, 2020).

Pix é o pagamento instantâneo brasileiro. O meio de pagamento criado pelo Banco Central (BC) em que os recursos são transferidos entre contas em poucos segundos, a qualquer hora ou dia. É prático, rápido e seguro. O Pix pode ser realizado a partir de uma conta corrente, conta poupança ou conta de pagamento pré-paga (BRASIL, 2020).

\section{METODOLOGIA}

Para o desenvolvimento deste artigo, efetuou-se uma prospecção tecnológica de cunho exploratório, com busca qualitativa de patentes em bancos de dados para construção e análise de gráficos, com o objetivo de mapear as tendências tecnológicas no cenário mundial para carteiras digitais ou e-wallets.

Foi utilizada para a realização da busca de anterioridade, a plataforma de base de dados, Questel Orbit, no quesito pedido de depósitos de patentes. Em seguida, foram determinados os descritores tanto em Português quanto em Inglês, para serem utilizados nos processos de rota tecnológica. 
A coleta de dados foi realizada em setembro de 202I, e utilizou como estratégia de busca o campo pesquisa avançada para os seguintes termos em português - carteiras digitais; pagamento eletrônico; e em inglês, foram usados os termos - electronicpayment; paymentprotocols; walletdevices; digital walletpayment. Na referida pesquisa, foi usado o operador boleano AND, o qual funciona como a palavra "e", fornecendo a intercessão, ou seja, mostra os artigos que contenham todas as palavras chaves digitadas, restringindo a amplitude da pesquisa. Em complementação à busca, foram aplicados nos campos da estratégia - o Título, o Resumo e o IPC-International Patent Classification, administrado pela Organização Mundial da Propriedade Intelectual - OMPI, com a finalidade de obter um resultado mais eficaz para o resultado da pesquisa.

Os documentos encontrados foram analisados individualmente, com o intuito de caracterizar as patentes quanto às aplicações mencionadas, aos detentores destas, aos países com relevâncias inventivas e suas respectivas áreas de concentração a partir da Classificação Internacional de Patentes - IPC.

A pesquisa identificou II4 documentos de pedidos de depósitos de patentes na base de dados investigados, entretanto, para verificação de quais dessas patentes possuíam relação com o tema estudado, optou-se por realizar a leitura de todos os resumos, classificando-as conforme suas aplicações mencionadas aos resumos ou às reivindicações.

A mineração dos dados obtida foi apresentada nessa pesquisa, sob a forma de gráficos para discussão das tendências tecnológicas relacionadas ao tema proposto.

\section{RESULTADOS E DISCUSSÃO}

O avanço tecnológico nos últimos anos tem alterado os nossos hábitos cotidianos, e isso tem se refletido na forma como trabalhamos, como escutamos música, como nos conectamos a outras pessoas. Não seria diferente com a relação às transformações financeiras, e as consequências dessas mudanças relacionadas à moeda e a importância dela no mundo vigente. Em um tempo remoto, as cédulas de papel foram gradativamente sendo substituídas por cartões de plástico, atualmente, os mencionados cartões estão perdendo espaço para os dispositivos eletrônicos de pagamentos. É diante desse cenário, que surge a carteira digital ou e-wallets.

Conforme definição de Aleixo (2019), o e-wallet é um aplicativo de software, que permite a realização de pagamentos eletrônicos sem o uso de moeda em espécie ou cartões físicos pelos consumidores. Ele oferece ao usuário a capacidade de realizar pagamentos entre pessoas, além de compras por aplicativo celular ou on-line, bem como pagamentos em loja física usando um smartphone. 
Nos últimos anos, o Brasil iniciou os processos financeiros das chamadas carteiras digitais, dentre as quais estão contidas - Google Pay ${ }^{\mathrm{TM}}$, Apple Pay e Samsung Pay. A partir daí, foi desenvolvida uma nova opção de pagamento ao consumidor, o qual após realizar suas compras, concretizará o pagamento por aproximação do celular a um terminal de check-out, cujo sensor fará a leitura do aplicativo acoplado àquele, e debitará o valor automaticamente (ADYEN, 2019).

No cenário interno, a tecnologia ainda é incipiente, uma vez que a comodidade e a falta de informação causam desconfiança aos consumidores, porém já é uma realidade presente em vários países ao redor do mundo, no qual o setor de soluções digitais de pagamento prospecta um crescimento progressivo para os próximos anos. A constatação vem do Relatório Global de Pagamentos do Worldpay de 2018 da Global Payment Reports, que analisa a evolução do mercado de pagamentos (CABALLERO, 2019).

\section{TENDÊNCIAS TECNOLÓGICAS}

O uso de carteira digital é quase uma conseqüência natural na rotina das pessoas. Ao analisar as tendências tecnológicas como um todo, principalmente, no que se refere à utilização de aplicativos para pagamentos, o "digital wallets," vem sendo incorporado às transações financeiras, e, a tendência é tornar-se mais frequente entre os consumidores por conta da comodidade em realizar pagamento com apenas um toque na tela do aparelho, otimizando o processo final, além de evitar a emissão de comprovante, e contribuir dessa forma, com um ambiente mais sustentável.

O progresso tecnológico, cada vez mais, cria demanda para a utilização de soluções práticas, que almejam trazer simplicidade, viabilidade, interoperabilidade, segurança, integridade, autenticidade, disponibilidade, escalabilidade, desempenho e, sobretudo comodidade para atividades do cotidiano como aplicativo de pagamentos de contas e compras pela internet. Essa praticidade voltada para o contexto da Internet das Coisas (Iot), no qual comunicação, tecnologia e informação (TIC) estão devidamente conectadas (GALEGALE et al, 2016).A chamada Internet das Coisas (ou Internet of Things, Iot em inglês), é um conceito amplamente discernido por especialistas e estudiosos como o futuro da sociedade, no qual a internet promoverá uma interação ainda maior das pessoas com os objetos de contato e uso diários (GALEGALE et al, 2or6). Soluções digitais, como BePay, PayPal, Pagseguro, MercadoPago, Google Wallet, Apple são exemplos concretos de tendências tecnológicas que estão crescendo e se consolidando na vida das pessoas.

De acordo com a Figura I, é possível observar um cenário que teve suas raízes em 1998 e a perspectiva é de que o volume de depósitos de patentes continue a crescer no ano de 2019. $\mathrm{O}$ 
uso de carteiras digitais tem aumentando, significativamente, nos últimos anos; é possível observar, uma ocorrência maior no número de registros de patentes publicadas no período de 2014 a 2019, apresentando $14,14,17,17,20$ e 12 tecnologias protegidas, respectivamente, demonstrando uma tendência de investimento ligada à inovação financeira. A Figura or mostra o crescimento das publicações de patentes nas últimas décadas.

As patentes depositadas nos anos de 2019 a 2021 ainda estão afetadas pelos I8 meses de sigilo, por isso, não puderam ser discutidos nesse estudo.Mediante Míguez et al. (2018) o período de sigilo corresponde ao momento entre a apresentação de um pedido de patente e sua publicação, que é variável dentre os diferentes escritórios mundiais; embora em alguns países, como o Brasil, o prazo mínimo de 18 meses ocorra após a data do pedido de depósito da patente.

Figura or - Tendência de investimento em tecnologia anual (A) e acumulativa (B) de depósitos de patente nos últimos 20 anos

A

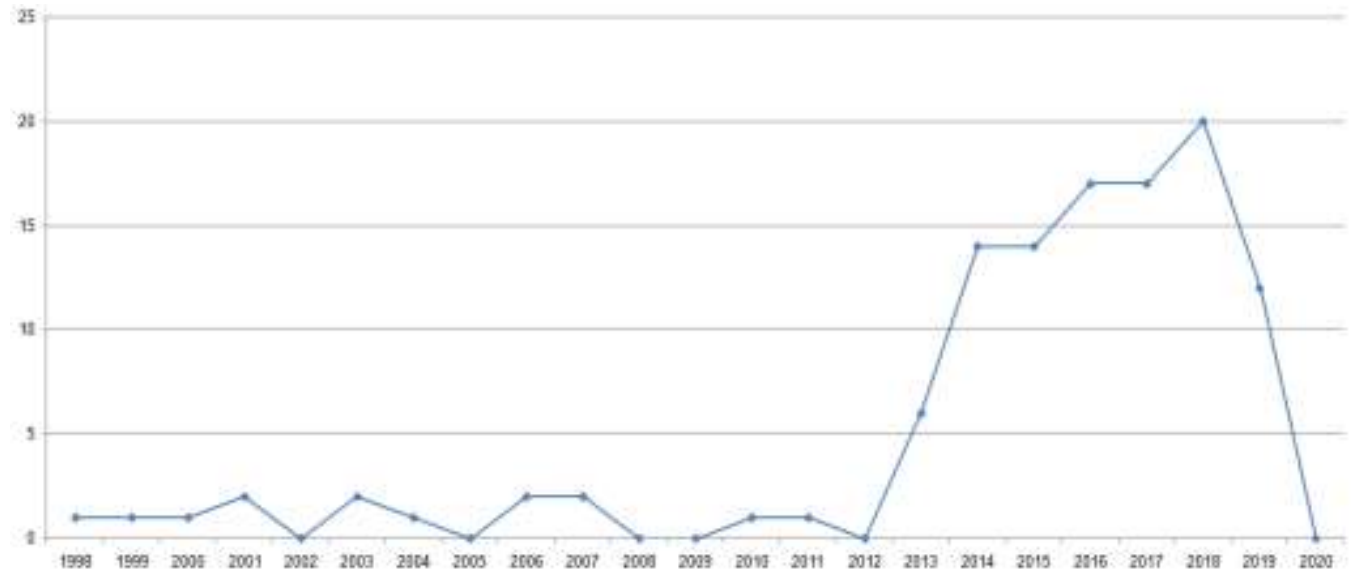

Fonte: Elaborado pelos autores com dados obtidos no Questel Orbit (2021).

B

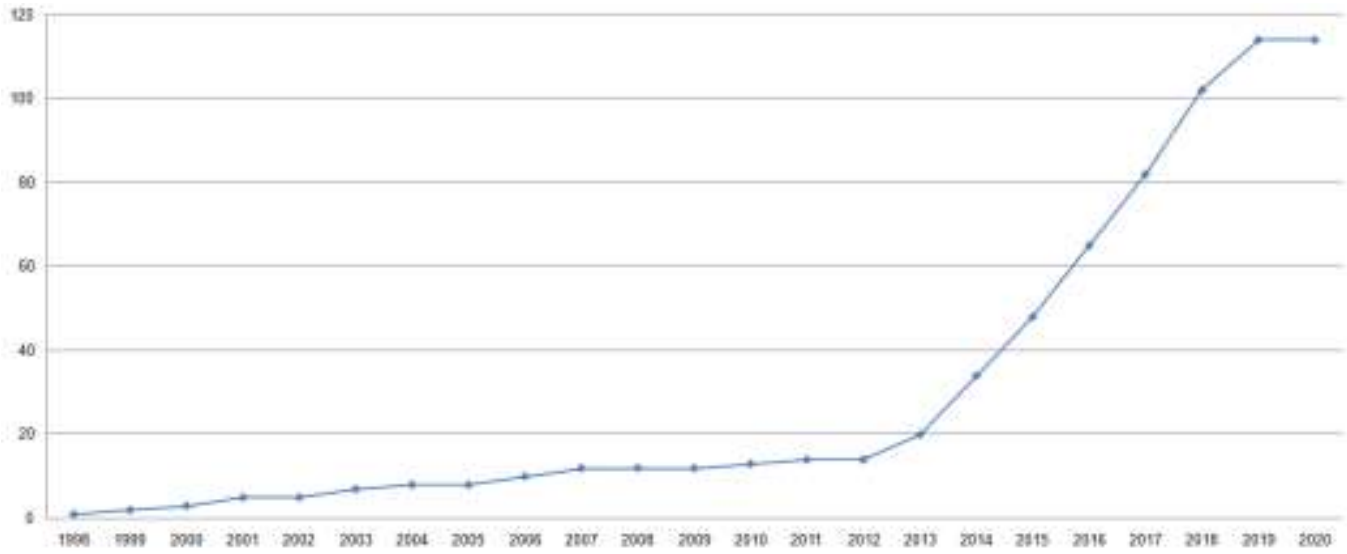

Fonte: Elaborado pelos autores com dados obtidos no Questel Orbit (2021). 
Em tempo, pode-se evidenciar um declínio no registro de patentes, principalmente no último ano, neste caso em 2020, no qual 12 (doze) tecnologias foram protegidas, e faz-se importante evidenciar uma redução do número de patentes por conta de eventuais atrasos nas análises das patentes pelos escritórios, os quais a tecnologia está vinculada aos pedidos protegidos.

A primeira patente identificada nesta investigação sobre o objeto de estudo, PI 9806416- 9 A, foi publicada pelo Instituto Nacional da Propriedade Industrial -INPI em is de novembro de 1999, via Tratado de Cooperação em Matéria de Patentes - PCT, cuja invenção descreve uma carteira virtual que permitem informações e serviços bancários financeiros, incluindo mecanismos de pagamento, mecanismos de autenticação de identidade, informação pessoais e artefatos eletrônicos (BRASIL,1999).

O primeiro país de prioridade é aquele onde a patente é protegida, originariamente, antes de ser (possivelmente) estendida a outros países (OECD, 2006). De maneira geral, os detentores titulares da tecnologia, que desejam proteger sua invenção em mais de um país, costumam reivindicar a prioridade de sua patente, primeiramente, em seu próprio país ou região para, posteriormente, procederem o pedido em outros países (WIPO, 2017).

Segundo Mies (2019), as carteiras digitais foram desenvolvidas para serem muito mais seguras que a navegação on-line, já que utilizam um código PIN gerado na hora ou o reconhecimento biométrico digital ou facial para identificar e autorizar a transação. Ou seja, os detalhes do cartão se tornam desnecessários, sendo substituídos por um identificador de dados, exclusivo e criptografado.

Figura 02 - Status Legal das tecnologias protegidas

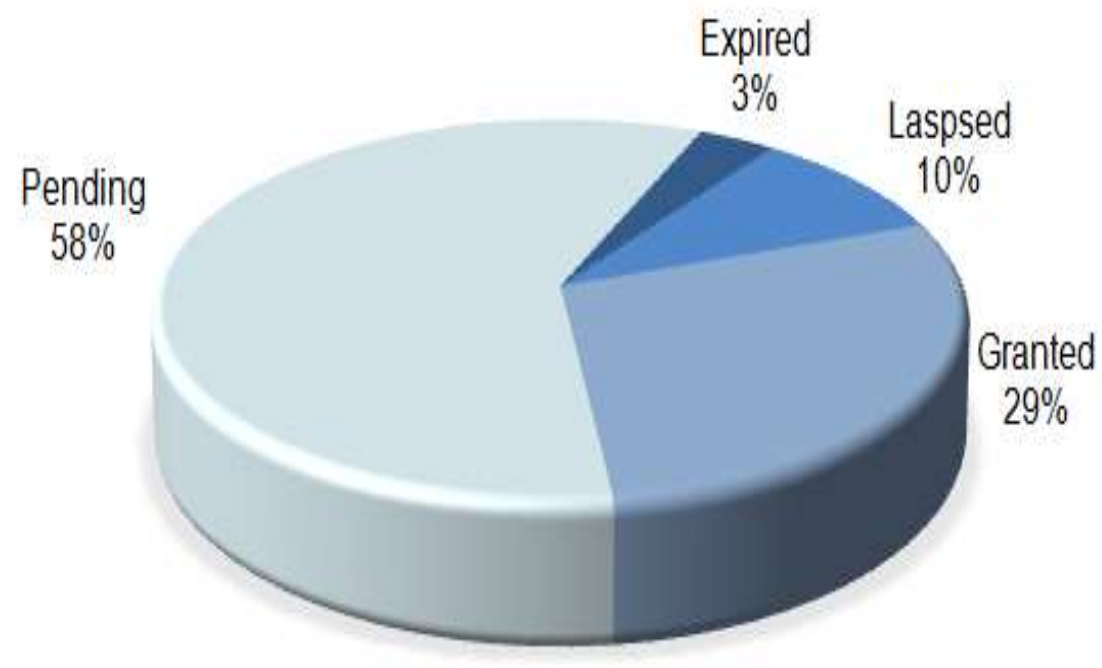

Fonte: Elaborado pelos autores com dados obtidos no Questel Orbit (2021). 
Os II4 depósitos de pedidos de patentes relacionados às carteiras digitais, identificados no banco de dados analisados, mostram que deste total - 58\% foram concedidos, $29 \%$ estão em análise técnica ou aguardando cumprimento de exigência, Io\% revogados e 3\% prescritos (Figura 2).

De acordo com Barbosa (2010), o inventor tem o direito temporário da tecnologia requerida perante o órgão responsável. A concessão da patente permite ao inventor a exploração da invenção, de maneira exclusiva, por prazo determinado, para que dessa forma seja capaz de auferir ganhos materiais que a mesma possa proporcionar, e quando finalizado esse prazo, e a invenção cair no domínio público, a patente poderá ser livremente usada e explorada (BARBOSA, 2010).

A Lei № 9.279/96 - Lei de Propriedade Industrial (LPI), regula direito e obrigações relativos à propriedade industrial, e determina em seu art.78 as formas de extinção da patente, e quando o objeto protegido cairá em domínio público (BRASIL, 1996):

$$
\begin{aligned}
& \text { I - pela expiração do prazo de vigência; } \\
& \text { II - pela renúncia de seu titular, ressalvado o direito de terceiros; } \\
& \text { III - pela caducidade; } \\
& \text { IV - pela falta de pagamento da retribuição anual, nos prazos previstos no } § \\
& \text { 2o do art. } 84 \text { e no art. } 87 \text {; e } \\
& \text { V - pela inobservância do disposto no art. } 217 \text {. }
\end{aligned}
$$

Conforme Coronata e Buscato (2017), o INPI leva em média io anos para concessão de uma carta patente. Nos Estados Unidos e na Europa, o tempo médio de espera para concessão de uma patente leva em torno de três anos; na China, leva-se em média dois anos aproximadamente; isso demonstra que o tempo de espera em cada nação é muito variável e provoca impactos importantes na economia nacional (CORONATA; BUSCATO, 2017).

Para determinadas empresas, a utilização estratégica no depósito de pedidos de patentes, tem como pressuposto uma garantia mínima de exclusividade sobre uma determinada tecnologia. Com a patente depositada, após análise de viabilidade econômica, muitas vezes, um empresário poderá observar que a tecnologia protegida pode não representar uma inovação lucrativa para sua empresa (SPEZIALI; SINISTERRA, 2015).

Neste contexto, o abandono do pedido de patente é uma decisão meramente estratégica, uma vez que algumas corporações, por questões mercadológicas decidem não explorar a tecnologia anteriormente protegida no pedido de patente, e nem permitir que o seu concorrente tambem o faça, porque uma vez que o relatório descritivo e as reivindicações sejam publicados, não existe mais a inovação, visto que a novidade já foi divulgada previamente. 
Figura 3 - Mapa mundial de países com tecnologias protegidas em carteiras digitais

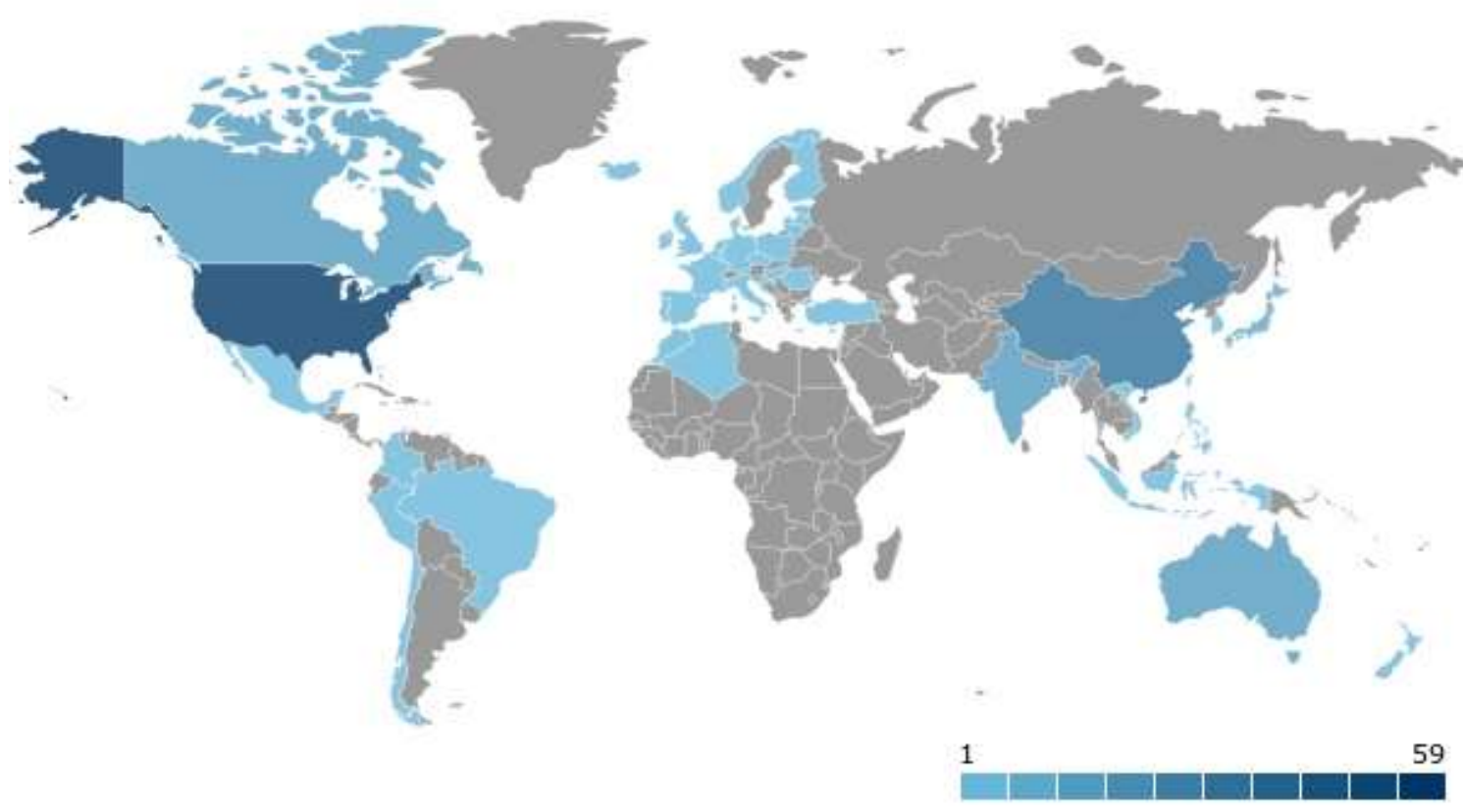

Fonte: Questel Orbit, 2021.

A Figura 3 sinaliza o mapa mundial de países detentores das tecnologias patenteadas em carteiras digitais. A cor cinza significa países sem patentes, e à proporção que a cor azul fica mais escura, significa o aumento no número de patentes.

Avaliando os documentos obtidos através da prospecção tecnológica, foi possível observar que os maiores países desenvolvedores dessa tecnologia, nesse caso os Estados Unidos da América lideramos resultados como sendo o país com maior número de publicações de patentes em carteiras digitais, principalmente, em razão do grande volume de vendas concentradas nos comércios da China, da Índia, dos EUA, e também nos países em desenvolvimento, como é o caso da África do Sul, como observado na Figura 04 e corroborado com a Figura 3.

Apesar de não ser uma tecnologia recente no Brasil, ela ainda não foi explorada o suficiente para computar indicadores expressivos nesse trabalho. $O$ uso das carteiras digitais já é comum em muitos países da Europa, Ásia e América do Norte, desde 20II, com o lançamento da Google Wallet para dispositivos Android (NOGUEIRA, 2020).

Segundo Nogueira (2020), a partir do ano de 2014, a Apple Pay lançou dispositivos IOS, e pulverizou ainda mais o uso da tecnologia desenvolvida, inicialmente, com foco apenas em pagamentos eletrônicos e, atualmente, conta com os serviços de armazenamento de 
carregamento de cartões pré-pagos, transferências de dinheiro em conta, gerenciamento de cartões de fidelidade e resgate de promoções em lojas.

Figura 04 - Distribuição de patentes por país da primeira prioridade

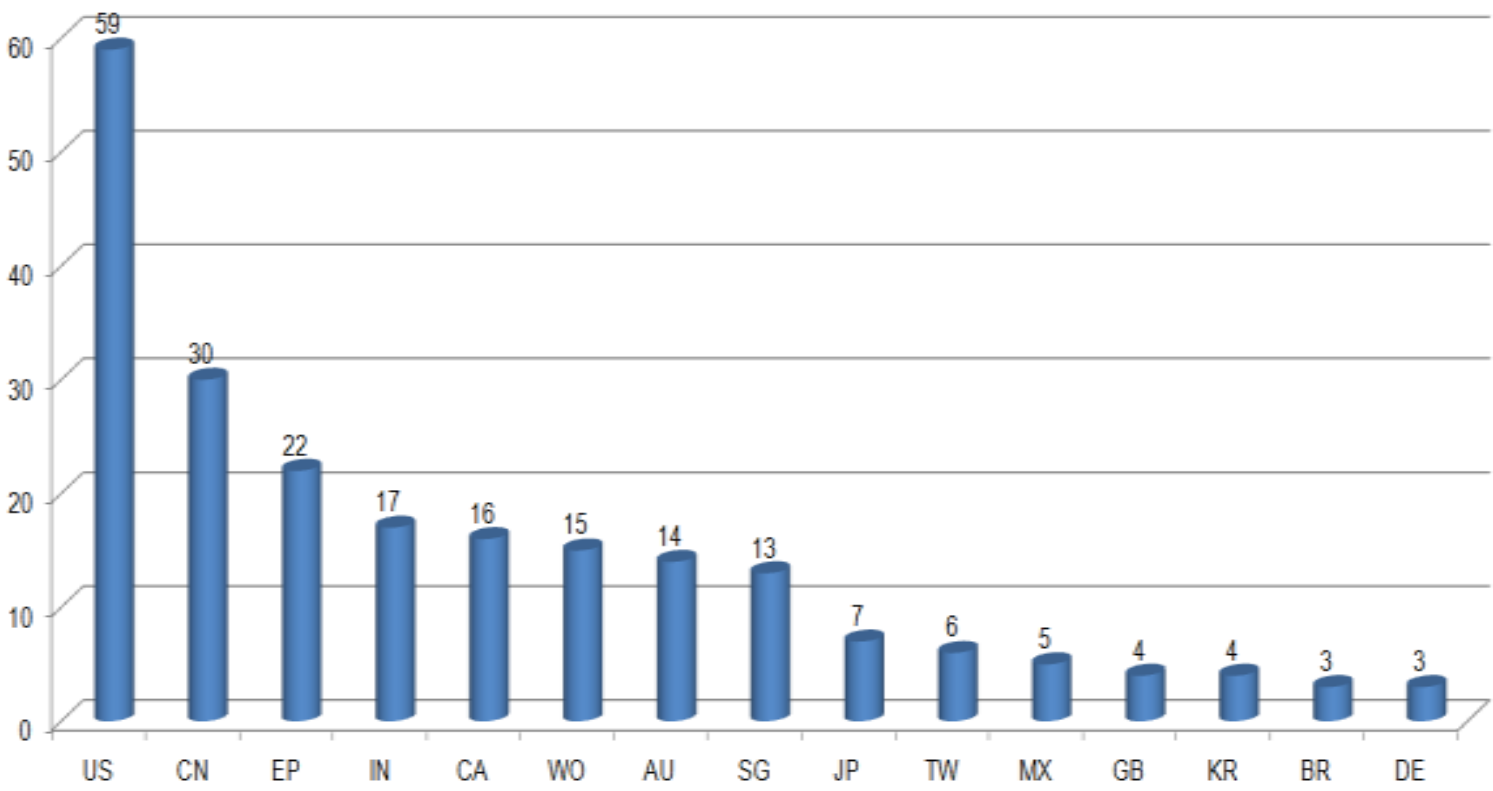

Fonte: Elaborado pelos autores com dados obtidos no Questel Orbit (202I).

O Canadá e o Escritório da Organização Mundial da Propriedade Intelectual (OMPI) também tiveram um número significativo de registros de tecnologias patentáveis, o Brasil por sua vez, figura na décima quarta colocação entre os países analisados, pode-se dizer que ainda é incipiente o desenvolvimento neste segmento.

De acordo com Meis (2019), nos Estados Unidos, a carteira digital Apple Pay tornou-se um dos principais recursos para pagamentos da rede de farmácias Walgreens.

A Walgreens é uma das maiores cadeias de farmácia dos Estados Unidos, com mais de 8.175 lojas em todos os 50 estados, o Distrito de Colúmbia, Porto Rico e as Ilhas Virgens dos Estados Unidos. A e-wallet é tão popular que foi associada ao programa de fidelidade da marca para aplicar descontos. A Apple vem estimando que 60\% das lojas americanas estejam integradas com o método de pagamento (RETAILSB, 2019).

Segundo o estudo da Adyen (2018), a China é o maior mercado de comércio eletrônico no mundo, onde aproximadamente $70 \%$ da população economicamente ativa do país têm nas carteiras digitais o principal meio de pagamento. As duas maiores e-wallets do país, WeChat $\mathrm{e}$ Alipay, movimentaram cerca de 3 trilhões de dólares em transações em 2016. O mesmo estudo aponta que outros países seguem a mesma tendência: $17 \%$ das transações feitas na Austrália e I4\% das realizadas na Índia já são feitas por e-wallets (ADYEN, 20ı8). 
A Índia saiu à frente com o $e$ - wallets com o app Paytm. São cerca de 350 milhões de usuários e 500 milhões de operações mensais. O governo indiano é o principal incentivador do uso dessa tecnologia, e tirou de circulação notas de maior valor para estimular o uso dos aplicativos. A alegação seria de que o digital wallets ajudaria a combater a corrupção, o dinheiro falso e o câmbio paralelo (CABALLERO, 2019).

Segundo Meis (2019), corroborando com o relatório da plataforma Adyen (2018) o uso do método de pagamentos cresceu 50\% só nos últimos três meses, mudando os paradigmas diante das transformações definitivas no uso do dinheiro físico e do cartão de crédito no país, atestando assim, que as carteiras digitais apareceram para liderar esse movimento (MEIS,2019).

Enquanto isso, no Brasil, quem promete expandir os negócios de digital wallets com mais rapidez são as multinacionais americana de serviços financeiros Visa e Mastercard e em seguida a francesa Ticket e o Banco Central com a chave Pix (ADYEN, 2018).

Segundo o Banco Central do Brasil (2022), o Pix pode ser utilizado para:

OS transferências entre pessoas;

OS pagamento em estabelecimentos comerciais, incluindo lojas físicas e comércio eletrônico;

OS pagamento de prestadores de serviços;

os pagamento entre empresas, como pagamentos de fornecedores, por exemplo;

os recolhimento de receitas de Órgãos Públicos Federais como taxas (custas judiciais, emissão de passaporte etc.), aluguéis de imóveis públicos, serviços administrativos e educacionais, multas, entre outros (esses recolhimentos poderão ser feitos por meio do PagTesouro);

OS pagamento de cobranças;

OS pagamento de faturas de serviços públicos, como energia elétrica, telecomunicações (telefone celular, internet, TV a cabo, telefone fixo) e abastecimento de água; e

OS recolhimento de contribuições do FGTS e da Contribuição Social.

Segundo a Associação Nacional das Empresas de Recuperação de Crédito (2018), 60 milhões de brasileiros, quase metade da população economicamente ativa, não possuem uma conta bancária.

Das invenções analisadas, $39 \%$ das patentes estão em propriedade das dez maiores empresas, conforme Figura 05. A crescente popularidade de soluções de pagamentos alternativos e o comércio digital em geral contribuem ainda mais para a tendência de eletronificação. O volume de comércio digital global no ano 2019 representa $14 \%$ do total de vendas de varejo no mundo, e no Brasil o faturamento cresce I8\% (SAMPAIO, 2020). 
Figura 05 - As principais empresas detentoras de patentes

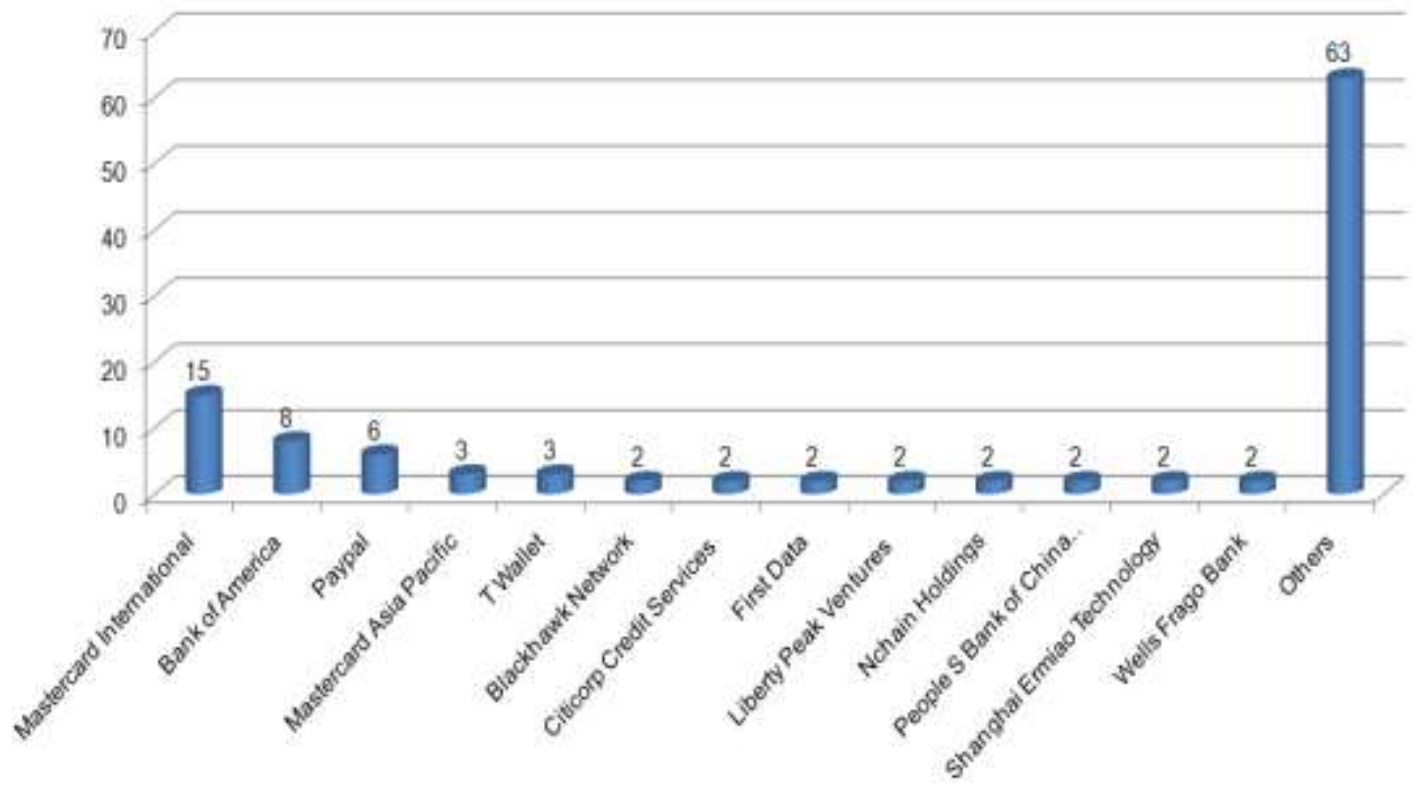

Fonte: Elaborado pelos autores com dados obtidos no Questel Orbit (2021).

Algumas das principais empresas detentoras em tecnologias de carteiras digitais no mercado internacional, conforme a figura o5 inclui a Mastercard Internacional $14,43 \%$, Bank of America 7,21\%, Paypal com 5,15\%, Mastercard Ásia Pacific 4,12\% e T. Wallet 3,09\%, entre outras.

Figura 06 - Indicadores das três maiores empresas em carteiras digitais

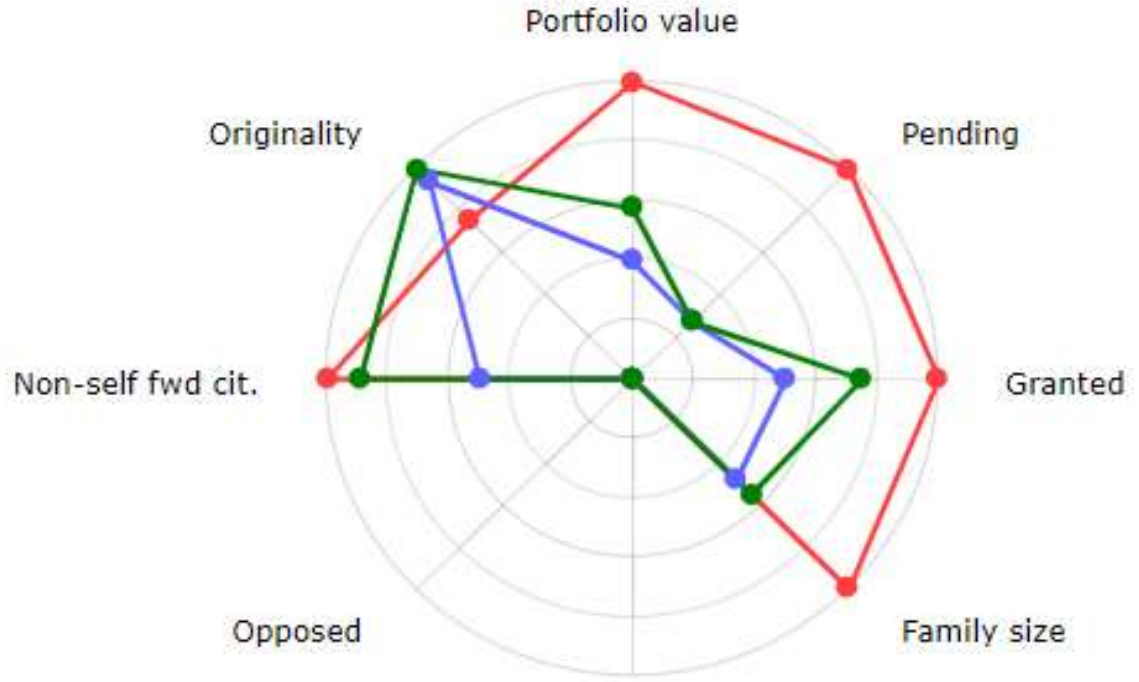

Litigated

Fonte: Questel Orbit, 2021. 
A Mastercard é uma empresa de tecnologia com foco na indústria global de pagamentos, que opera em rede de processamento de pagamento mais rápida do mundo, conectando consumidores, instituições financeiras, comerciantes, governos e empresas em mais de 2io países e territórios no mundo. Os produtos e as soluções da Mastercard tornam as atividades diárias - tais como fazer compras, viajar, administrar um negócio e gerir as finanças - mais fáceis, seguras e eficientes para todos (MEDEIROS, 2018).

A Mastercard Internacional é a maior detentora de patentes no mundo; a empresa registrou mais de 815 mil transações com carteiras digitais no Brasil entre janeiro e novembro de 2018, um salto de $800 \%$ quando comparado com as 90 mil transações no mesmo período de 2017 (MEDEIROS, 2018).

Os Estados Unidos e a Ásia-Pacífico já compreendem mais da metade desses US \$3 trilhões e, devido ao rápido crescimento do mercado chinês, aumentará sua participação para quase 70\% até 2022. O comércio móvel, incluindo pagamentos por aplicativo e pagamentos por navegadores móveis, é o fator dominante de um forte crescimento do comércio digital, devido à adoção crescente de smartphones, uma mudança crescente na forma de direcionar as compras on-line, e, consequentemente, melhorias na estrutura da largura de banda larga.

O PayPal fundado nos EUA em 1998 com o nome de Confinitypor Max Levchin, Luke Nosek, Peter Thiel e Ken Howery, tornou-se uma empresa responsável pelo desenvolvimento de softwares de segurança para dispositivos portáteis. Em I999, a Confinity transformou-se em um serviço de transferência de dinheiro e fundiu-se com a X.com, uma empresa Elon Musk em 2000, oferecendo serviços bancários pela Internet (ROSA, 2018).

Em 2002, o PayPal ganhou popularidade como um processador de pagamentos on-line, sendo adquirido em seguida pelo site eBay, tornando-se dessa forma, o serviço oficial de transferência de pagamentos para o referido site. O PayPal, a partir de 20I5, alcançou o ranking de uma das maiores empresas mundiais de pagamentos on-line, cujo negócio permite às partes envolvidas na transação, realizarem pagamentos por meio de transferências de fundos on-line. A empresa fornece sua plataforma de tecnologia e pagamentos digitais para usuários de e-commerce, comerciantes, fornecedores on-line e indivíduos que desejam transferir ou receber fundos eletronicamente de maneira segura (ROSA, 2018).

\section{CONCLUSÃO}

Neste estudo, a proposta foi identificar as carteiras digitais (digital wallet em inglês) e o estado da técnica no cenário global das patentes e da literatura como forma de analisar os principais detentores e concorrentes dos segmentos da tecnologia estudada. Para tanto, foi 
proposta uma pesquisa exploratória de cunho qualitativa, fundamentada em uma tendência tecnológica que foi amplamente explorada na base de dados de patentes da plataforma do Questel Orbit.

A prospecção realizada demonstrou que os Estados Unidos possuem o maior número de depósitos de patentes desse setor, enquanto no Brasil os resultados mostraram que a inovação proposta na pesquisa em andamento ainda é de conhecimento restrito, ou seja, são incipientes.

Os dados apresentados neste estudo, assim como a ausência de pesquisa sobre a temática deste artigo, revelam à necessidade de investimentos no desenvolvimento de tecnologias em carteiras digitais no Brasil. A tecnologia em e-wallet não é tão revolucionária quanto parece, ela existe no Brasil há mais de io anos. Uma das barreiras que impediu seu deslanche por muito tempo foi à desconfiança em relação à segurança por parte dos usuários. Porém, para garantir a confiabilidade nos sistemas digitais de pagamento é imprescindível a segurança da informação garantida pelas empresas responsáveis pelo serviço.

Apesar de já ser uma tendência mundial, as carteiras digitais passaram a ganhar mais força a partir de 2021, principalmente, pela pandemia de coronavírus (Covid-ı) que forçaram os pagamentos instantâneos, por reduzirem o contato direto das pessoas com o dinheiro.

\section{REFERÊNCIAS}

ADYEN. Infográfico: como as pessoas. 21/12/2018. Disponível em: <https://www.adyen.com/pt_BR/blog/infografico-como-as-pessoas-pagam-ao-redordo-mundo>. Acesso em or nov. 2021.

ADYEN. Carteiras digitais: o que são como funcionam e que vantagens trazem. 27/ri/2019. Disponível em: <https://www.adyen.com/pt_BR/blog/carteiras-digitais-oque-sao-como-funcionam-e-que-vantagens-trazem>. Acesso em o5 dez. 2021.

BANCO CENTRAL DO BRASIL. O que é Pix? Disponível em: https://www.bcb.gov.br/estabilidadefinanceira/pix. Acesso em is jan. 2022.

ALEIXO D. Tutoriais e Soluções. O que é uma carteira digital (e-wallet). 25/or/2019. Disponível em: <https://help.vtex.com/tutorial/o-que-e-uma-carteira-digital-ewallet?locale $=$ pt $>$. Acesso em ir jan. 2022 .

BARBOSA, Denis Borges. Tratado da Propriedade Intelectual. Rio de Janeiro: Lumen Iuris, 2010. 
BRASIL. BANCO CENTRAL DO BRASIL (BCB) . BC Lança Sistema de pagamento instantâneo no Brasil. Disponível em https://agenciabrasil.ebc.com.br/economia/noticia/2020-02/bc-lanca-sistema-depagamento-instantaneo-no-brasil $>$. Acesso em is jan 2021.

BRASIL. Lei no 9.279/96, de I4 de maio de 1996. Regula direitos e obrigações relativos à propriedade industrial. Diário Oficial da República Federativa do Brasil. Brasília, I4 maio 1996. Disponível em: http://www.planalto.gov.br/CCIVIL/Leis/L9279.htm. Acesso em: or dez. 2021.

BRASIL. INPI. Instituto Nacional de Propriedade Industrial. Introdução à classificação internacional de patentes. São Paulo, 2014.

CABALLERO, Cássia. Digital wallet: pagamento por aproximação. 30/o4/2019. Disponível em <https://www.destakjornal.com.br/seu-valor/detalhe/digital-walletpagamento-por-aproximacao >. Acesso em 06 dez. 202I.

COROnATA, M. BUSCATO, M. Aprovação Rápida de Patente Beneficia a Sociedade. 17/o8/2017. Disponivel em: <http://epoca.globo.com/economia /aprovacaorapida-de-patentes-beneficia-sociedade.html>. Acesso em 29 de dez. de 2021.

DOS SANTOS AMPARO, Keize Katiane; RIBEIRO, Maria do Carmo Oliveira; GUARIEIRO, Lilian Lefol Nani. Estudo de caso utilizando mapeamento de prospecção tecnológica como principal ferramenta de busca científica. Perspectivas em Ciência da Informação, v. 17, n. 4, p. 195- 209, 2012.

GALEGALE, G. P.; SIQUEIRA, E. ; Hilário, C. B. S.; SOUZA, A. Internet das coisas aplicada a negócios - um estudo bibliométrico. Revista de Gestão da Tecnologia e Sistemas de Informação, Vol. 13, No. 3, Set/Dez., 2016 pp. 423-438.

GLOBO.COM. Entenda o que é blockchain, a tecnologia por trás do bitcoin. Disponível em: <https://gi.globo.com/economia/noticia/entenda-o-que-e-blockchaina-tecnologia-por-tras-do-bitcoin.ghtml>. Acesso em: or dez. 2021.

MIES J. C. Carteiras digitais: O próximo passo da mobilidade. 07/or/2019. Disponível em 〈https://ecommercenews.com.br/artigos/tendencias-artigos/carteiras-digitais-oproximo-passo-da-mobilidade/ $>$. Acesso em I2 nov. de 202I. 
MEDEIROS $H$. Mastercard mira futuro mais digital e sem dinheiro físico. $06 / 12 / 2018$.

<https://www.mobiletime.com.br/noticias/o6/12/2018/mastercard-mira-futuro-maisdigital-e-sem-dinheiro-fisico-diz-presidente/>. Acesso em I2 jan de 2022.

Míguez J L, Porteiro J, Pérez-orozco R, Patiño D, Rodríguez S. Evolutionof CO $^{2}$ capture technologybetween 2007 and 2017 throughthestudyofpatentactivity. Applied Energy. 2II 2018; I282-1296.https://doi.org/10.1016/j.apenergy.2017.11.107

NOGUEIRA, L. Carteiras digitais é o futuro da mobilidade, 2020. Disponível $<$ http://cantarinobrasileiro.com.br/blog/carteiras-digitais-sao-o-futuro-da-mobilidade2/>. Acesso 14 dez. 2021

\section{ORGANIZAÇÃO PARA A COOPERAÇÃO E DESENVOLVIMENTO} ECONÓMICO (OECD). Glossary of Patent Terminology. 20o6. Disponível em: . Acesso em: io jan. 202I.

ORBIT QUESTEL. Ferramenta de busca de bases de dados - Internet. (CQuestel; 2020. Disponível em: www.orbit.com. Acesso em: setembro de 202I.

Paltenghe, Cris T. Takata, Melvin Michio. Mamdani, Alnoor Bahdur . Huddleston, Gregory Lee . Citicorp Development Center, Inc. Rede de distribuição com base numa carteira eletrônica. BRASIL. PI 9806416-9. I2.II.1998. Disponivel em: < https://gru.inpi.gov.br/pePI/servlet/PatenteServletController?Action=detail\&CodPed ido $=51484 \mathrm{I} \&$ SearchParameter $=$ PI 9806416-9>. Acesso em 29 de setembro de 2021.

ROSA, Natalie. PayPal 20 anos-Conheça a história da empresa de pagamentos online. 20.12.2018. Disponível em <https://canaltech.com.br/mercado/paypal-20-anos-conhecaa-historia-da-empresa-de-pagamentos-online-12886I/>. Acesso em 05 jan. 202I.

RETAILSB. Sobre a Walgreens Pharmacies. 17/06/2019. Disponivel em: 〈http://diarioretailsudamericabusiness.com/usa/directory/walgreens-farmacias/〉. Acesso em or jan. 2022.

SAMPAIO, D. O que é E-Commerce? Tudo que você precisa para ter uma loja virtual de sucesso!, 2020. Disponível 〈https://rockcontent.com/blog/e-commerce-guia/〉. Acesso em I2 dez. 2021. 
SEGS. Associação Nacional das Empresas de Recuperação de Crédito. 25.10.2018. Disponível em:<http://www.aserc.org.br/2018/ro/25/cerca-de-30-da-populacaobrasileira-nao-possui-conta-em-banco/>. Acesso em o5 dez. 2021.

SILVA, W. H. N. Sistema de Bilhetagem Eletrônica: Tendências no Modal de Transporte Coletivo. 2017. no $\mathrm{n}^{\mathrm{O}}$. Centro de Ciências Sociais Aplicadas - Universidade Federal do Rio Grande do Norte, Nata, 2017.

SPEZIALI, Marcelo Gomes; SINISTERRA, Rubén Dario. Buscas de Informações Tecnológicas com Base de Dados de Patentes: Estudo de Caso dos Líquidos Iônicos no Brasil. Química Nova, São Paulo, v. 38, n. 8, 2015. Disponível em:〈http://www.scielo.br/scielo.php?script=sci_arttext\&pid=Soroo-4042201500080113>. Acesso em: o9 de jan. de 2022.

WORLD INTELLECTUAL PROPERTY ORGANIZATION (WIPO). Patent Cooperation Treaty (PCT). WIPO: Washington, 1970. Disponível em: o9 jan. 2022. 